\title{
Nutrition Information Sources Used By Amateur Bodybuilding Athletes Around Polokwane Municipality In Limpopo Province, South Africa
}

Sylven Masoga ( $\sim$ sylven.masoga@ul.ac.za )

University of Limpopo

Research

Keywords: Bodybuilding, Athletes, Nutrition Information, Sport

Posted Date: November 1st, 2021

DOl: https://doi.org/10.21203/rs.3.rs-978867/v1

License: (c) (i) This work is licensed under a Creative Commons Attribution 4.0 International License.

Read Full License 


\section{Abstract}

Background: There is a growing number of athletes participating in bodybuilding sport around the Limpopo Province. However, little is known about the nutrition information sources used by these athletes to guide their decisions during sports performance. Therefore, the researcher aimed at closing this gap through the investigation of nutrition information sources used by the bodybuilding athletes around one of the largest municipalities (Polokwane) in Limpopo Province.

Methods: A quantitative descriptive study design was adopted to purposively sample 51 out of 60 amateur bodybuilding athletes in gyms around Polokwane municipality. Ethical approval and permission were obtained from the MEDUNSA Research and Ethics Committee (MREC) and coaches respectively. Athletes signed informed consent forms after the purpose of the study was explained. Data were collected at gyms in the evenings using self-designed questionnaires. The athletes' demography, training information, and nutrition sources were collected. The SPSS (23) was used to analyse data using descriptive tests.

Results: A Few athletes (11.8\%) trained as bodybuilders for $\leq 6$ months, while most athletes $(66.7 \%)$ had been training for $>7$ months to 2 years. The majority $(86.3 \%)$ trained for $\geq 1$ hour during weekdays. Most of the athletes (37.3\%) relied on coaches as their source of information, while $29.4 \%$ and $29.3 \%$ relied on social media and teammates respectively. Only $4.0 \%$ used a professional for nutrition information.

Conclusion: The bodybuilding athletes around Polokwane municipality mostly used coaches as sources for nutritional information.

Trial registration: Not Applicable.

\section{Introduction}

Bodybuilding sports involve regular exercises designed to increase muscle strength and size ${ }^{1}$. These athletes are judged on muscle size, shape, definition, proportionality, and visual presentation ${ }^{2}$. This composition of high muscles and low body fat percentages is most likely to be achieved through the use of various nutrition evidence-based diets, training support and anabolic agents ${ }^{3}$. Two phases govern this sport: bulking and cutting. Bulking entails the gaining of muscles and this occurs mostly throughout the year, during which time weight gain becomes common ${ }^{2}$. The second strategy is cutting where the body fat loss is encouraged with minimal loss of muscle mostly conducted during the $12-14$ weeks before the competition. Cutting generally involves reducing energy intake and increasing aerobic exercise while monitoring body fat percentage. The relative absence of fat improves the appearance of muscles by revealing the muscle size, shape, and striation ${ }^{3}$. Nutrition plays a significant role in three aspects of training athletes: fueling of sport-specific and strength training, recovery from the training, and the promotion of training adaptations, including skeletal muscle hypertrophy ${ }^{4}$. Bodybuilding athletes generally hold different theories of information around nutrition, diets, and medication ${ }^{5}$. However, the 
current researcher believes that reliable (evidence-based/scientific) nutrition information source(s) are essential and should be adopted during every phase of bodybuilding training. This would assist athletes in making precise decisions on their dietary practices and/or choices, which in turn, will support performance and promote good health. The current researcher has observed that bodybuilding sport is progressively gaining popularity among the black African individuals around Polokwane municipality of Limpopo province. In this municipal area, the majority of the sections are classified as rural, dominated by Pedi, Tsonga, and the Venda language-speaking ethnic groups. The majority of the bodybuilding athletes attend training and exercise in various gyms of this municipality. The dietary intake of these bodybuilding athletes has been reported to be suboptimal ${ }^{6}$. However, the nutrition information sources used by Polokwane municipality athletes were scarcely reported. It is important for the nutrition information sources of these athletes to be extensively reported to guide or encourage them towards usage of reliable nutrition information sources as a practice; and further, encourage consultancy or utilisation of appropriate nutrition professionals for bodybuilding sports.

\section{Methods}

A quantitative descriptive study design was adopted in a larger study 6 to recruit 51 out of the 65 bodybuilding athletes in various gyms around the Polokwane municipality. A purposive sampling technique was used to obtain these athletes given the limited number of individuals (65) who participated in bodybuilding sports at that time. These athletes were affiliated members of the IFBBSA in Limpopo and registered members in their different gyms. Ethical clearance for this study was obtained from the MEDUNSA Research committee (MREC) (MREC/HS/251/2014:PG). The researcher further obtained approval from the Polokwane bodybuilding gyms through the coaches before conducting the study. Athletes signed the written consent forms before the study could be undertaken. Data collection was done at the gym centers in the evening, just before the commencement of the training session. The selfdesigned questionnaires with three sections covering the demographic information (age, gender and marital status), training information (number of years involved in bodybuilding, duration of training and frequency of training in a week), and nutrition information sources (coaches, social media and teammates) were used. Athletes filled in the questionnaire themselves, with the onsite availability of the researcher for support or clarity where the need arose. Data were loaded onto the Statistical Package for Social Sciences (SPSS) version 23 and analysed. All the descriptive variables were expressed as percentages, ranges, mean values, and standard deviations $( \pm S D)$.

\section{Results}

Results of the 51 bodybuilding athletes are presented in figures $(1-3)$ and tables $(1-2)$. 
Table 1

Gender among the athletes. There were fewer females (5.9\%) than males (94.1\%).

\begin{tabular}{|lll|}
\hline Gender & Frequency $(\mathbf{n = 5 1 )}$ & Percent \\
\hline Male & 48 & 94.1 \\
Female & 3 & 5.9 \\
\hline
\end{tabular}

Information regarding the number of years in which the participants have been engaging in bodybuilding sport was collected and the results are presented in Fig. 2.

Table 2

illustrates the training duration that was spent by the bodybuilding athletes each day. The majority trained for an hour or more, 2 - 3 times per week.

\begin{tabular}{|lll|}
\hline Duration per day & Frequency $(\mathbf{n = 5 1 )}$ & Percent (\%) \\
\hline $30-45 \mathrm{~min}$ & 1 & 2.0 \\
\hline $45 \mathrm{~min}-1 \mathrm{hr}$. & 6 & 11.8 \\
\hline$>1$ hour & 44 & 86.3 \\
\hline Duration per week & Frequency & Percent (\%) \\
\hline Once & 15 & 29.4 \\
\hline $2-3$ times & 32 & 62.7 \\
\hline $4-5$ times & 4 & 7.8 \\
\hline
\end{tabular}

The graph below illustrates the source of nutrition information used by bodybuilding athletes.

\section{Discussion}

\section{Demography}

The study collected data from a total number of 51 bodybuilding athletes implying a response rate of $78 \%$. The mean age of the athletes was $23.6( \pm 3.2)$ years. These findings are comparable to those reported by Monteiro and colleagues ${ }^{7}$. In their study, a sample of 33 athletes was studied. Additionally, Gaines (2001) found a total sample of 37 while comparing the anthropometry of competitive bodybuilders to judge's score ${ }^{8}$. However, Ogita, 2010 and Trabelsi et al., 2012 obtained fewer (27 or less) participants during their investigations ${ }^{9,10}$. Even lower samples $(n=\leq 18)$ of athletes were used by Lenzi et al. (2019); Mitchel et al. (2017) and Trabelsi et al. (2012) during the investigations of bodybuilders' body composition and anthropometry $2,11,10$. Similar to these bodybuilding studies, the researcher in the current study obtained smaller samples. This could suggest that bodybuilding sport has not yet gained sufficient 
popularity, especially among women, around Polokwane Municipality. Also, given the nature of this sport, it is suspected that there could be less interest for participation by individuals around the Municipality.

In the current study, almost all (94.1\%) of the athletes were males. Again, these results are divergent to those by Monteiro and colleagues (2012) who in their study had a fair gender distribution of $54.5 \%$ and $45.5 \%$ for men and women bodybuilders' respectively ${ }^{12}$. However, in a study by Gaines (2001) majority were males $(78.3 \%)$ than their counterparts $(21.6 \%)$ females $^{8}$. It is, therefore, not uncommon for bodybuilding sport to be predominated by males around the Polokwane municipality.

A two-thirds majority of the athletes $(66.8 \%)$ in the current study participated in bodybuilding sport for a period of 6 months to 2 years; the majority of whom (86.3\%) trained for an hour or more, $2-3$ times per week. The duration spend during training influences the fatty acids and carbohydrates oxidation ${ }^{13}$. Furthermore, in the review article by Barakat et al. (2020), it is emphasised that the extent of muscle gain and fat loss among individuals may be influenced by several things, among others, the training status, exercise interventions, and the individual's body composition status at baseline ${ }^{14}$.

\section{Nutrition information sources}

The most commonly used nutritional information sources by athletes in the current study were coaches (37.3\%), followed by both social media (29.4\%) and teammates $(29.3 \%)$. Of those who used social media, more than two-third relied on internet search while the rest used Facebook. In all the studied gyms, coaches offered bodybuilding sports training guidance, possibly making athletes count on them for nutritional guide and/or recommendations. The latter is factual for a study conducted among bodybuilding athletes on strategies during different competitive cycles. In the very previous study, $>60 \%$ of the athletes used the self-management approach, coaches, and websites as their strategies for obtaining nutrition information ${ }^{11}$. In another study in Ahwaz (Iran) by Jazayeri and Amani (2004), almost half (47\%) of the trainers/coaches were reported to prescribe diet programs for the bodybuilding athletes. The majority (65.6\%) of these coaches studied by Jazayeri and Amani (2004), recognised protein and carbohydrates as the two most essential nutrients required for bodybuilding sports other than minerals and water ${ }^{15}$. Additionally, Mitchel et al. (2017) reported website media, fellow teammates, and coaches as the most commonly used sources for nutritional information by the athletes ${ }^{11}$. Relying on nutritional information sources such as coaches and/or social media may at times offer inconsistent or deviating evidence-based practices ${ }^{2}$ posing a threat to the health outcomes of athletes, sooner or later in life. For instance, in a study by Masoga et al. (2019), bodybuilding athletes around the Polokwane municipality were reported to consume macronutrients suboptimally ${ }^{6}$. The current researcher postulate that the nutrition information source used by the majority of these athletes in the latter study misguided them towards nutritionally unreliable standards.

\section{Conclusion And Recommendations}


This study aimed to determine the nutrition information sources used by the bodybuilding athletes around Polokwane Municipality. These athletes relied on gym coaches social media, and teammates, in that order, for their nutrition information sources. A nutrition professional was scarcely used. It is, therefore, recommended that nutrition experts, for instance, dietitians be involved in bodybuilding sports to offer support and/or guide related to nutrition practices, meal plans, and general healthy eating choices; for the athletes to enjoy their life-long bodybuilding career.

\section{Declarations}

\section{Ethics approval and consent to participate}

Ethical approval was obtained from the MEDUNSA Research committee (MREC)

(MREC/HS/251/2014:PG). Consent to participate was obtained from the athletes in a written form after the aim of the study was explained to them.

\section{Consent for publication}

Not applicable.

\section{Availability of data and materials}

The datasets used and/or analysed during the current study are available from the corresponding author on reasonable request.

\section{Competing interests}

There is no competing interest for this study

\section{Funding}

The study received no funding

\section{Authors' contributions}

Mr. S Masoga conducted the study, analysed the data, and wrote the manuscript

\section{Acknowledgements}

The researchers would like to acknowledge all bodybuilding athletes within the Polokwane Municipality for participating in the study.

\section{Authors' information}

The author is a lecturer, (MSc Dietetics) within the clinical discipline: Practice of Therapeutic NutritioN: Department of Human Nutrition and Dietetics of the University of Limpopo. 


\section{References}

1. Alves RC., Prestes J. Enes A. de Moraes, WMA. Trindade TB. de Salles BF. Aragon AA \& Souza-Junior TP. Training Programs Designed for Muscle Hypertrophy in Bodybuilders: A Narrative Review', Sports 2020; 8 (11): 149. https://doi.org/10.3390/sports8110149.

2. Lenzi JL. Teixeira EL. de Jesus G. Schoenfeld BJ \& de Salles Painelli V. Dietary Strategies of Modern Bodybuilders During Different Phases of the Competitive Cycle, Journal of Strength and Conditioning Research 2021; 35(9): 2546-2551. DOI: 10.1519/JSC.0000000000003169.

3. Spendlove J. Mitchell L. Gifford J. Hackett D. Slater G. Cobley S \& O'Connor H. Dietary Intake of Competitive Bodybuilders. Sports Medicine 2015; 45 (7): 1041-63. DOI:10.1007/s40279-015-0329-4.

4. Slatter G \& Phillips MS. Nutrition guidelines for strength sports: Sprinting, weightlifting, throwing events, and bodybuilding, Journal of Sports Sciences, 2011; 29 (1): 67-77. https://doi.org/10.1080/02640414.2011.574722.

5. King, K.M., Woltring, M.T. \& Jubenville, C.B. Amateur Bodybuilders and Their Perceptions of Supplements: A Qualitative Analysis, 2021; 4 (2): 1-7.

6. Masoga S, Makuse SHM \& Bopape MM. Dietary Intake of Amateur Bodybuilding Athletes around Polokwane Municipality in Limpopo Province, South Africa. Global Journal of Health Science 2019; 11 (9): 1-9. DOI:10.5539/gjhs.v11n9p134

7. Monteiro JCV. Pimentel GD \& Sousa MV. Relationship between Body Mass Index with dietary fiber intake and skinfolds-differences among bodybuilders who train during morning and nocturne period; Nutricia Hospital 2012; 27 (3): 929-935.

8. Gaines RP. Comparison of Anthropometric Measures of Competitive Bodybuilders to Judges' Scores and a Comparison of Judges' Scores; Research dissertation 2001; 49-60

9. Ogita S. The Effects of Body Composition Differences on Placement at Bodybuilding Competition Among Male Amateur Bodybuilders. Research Papers 2001; 15-22

10. Trabelsi K. Stannard SR. Maughan R J. Jammoussi K. Zeghal K. \& Hakim A. Effect of Resistance Training During Ramadan on Body Composition and Markers of Renal Function, Metabolism, Inflammation, and Immunity in Recreational Bodybuilders; International Journal of Sports Nutrition and Exercise Metabolism 2012; 22: 267-275. DOI:10.1123/ijsnem.22.4.267

11. Mitchell L. Hackett D. Gifford J. Estermann F. \& O'Connor H. Do Bodybuilders Use Evidence-Based Nutrition Strategies to Manipulate Physique?', Sports 2017; 5 (4): 76. DOI: 10.3390/sports5040076

12. Monteiro JCV. Pimentel GD. Sousa MV. Relationship between Body Mass Index with dietary fiber intake and skinfolds-differences among bodybuilders who train during morning and nocturne period; Nutricia Hospital 2012; 27 (3): 929-935. DOI: 10.3305/nh.2012.27.3.5578.

13. Purdom, T., Kravitz, L., Dokladny, K. \& Mermier, C. Understanding the factors that effect maximal fat oxidation', Journal of the International Society of Sports Nutrition, 2018; 15(1):1-10. https://doi.org/10.1186/s12970-018-0207-1. 
14. Barakat C. Pearson J. Escalante G. Campbell B. \& De Souza E. Body Recomposition: Can Trained Individuals Build Muscle and Lose Fat at the Same Time?', Strength \& Conditioning Journal 2020; 42(5): 7. DOI:10.1519/SSC.0000000000000584.

15. Jazayeri, SMHM \& Amani R. Nutritional Knowledge, Attitudes and Practices of Bodybuilding Trainers in Ahwaz, Iran; Pakistan Journal of Nutrition 2004; 3(4): 228-231. DOI: 10.3923/pjn.2004.228.231

\section{Figures}

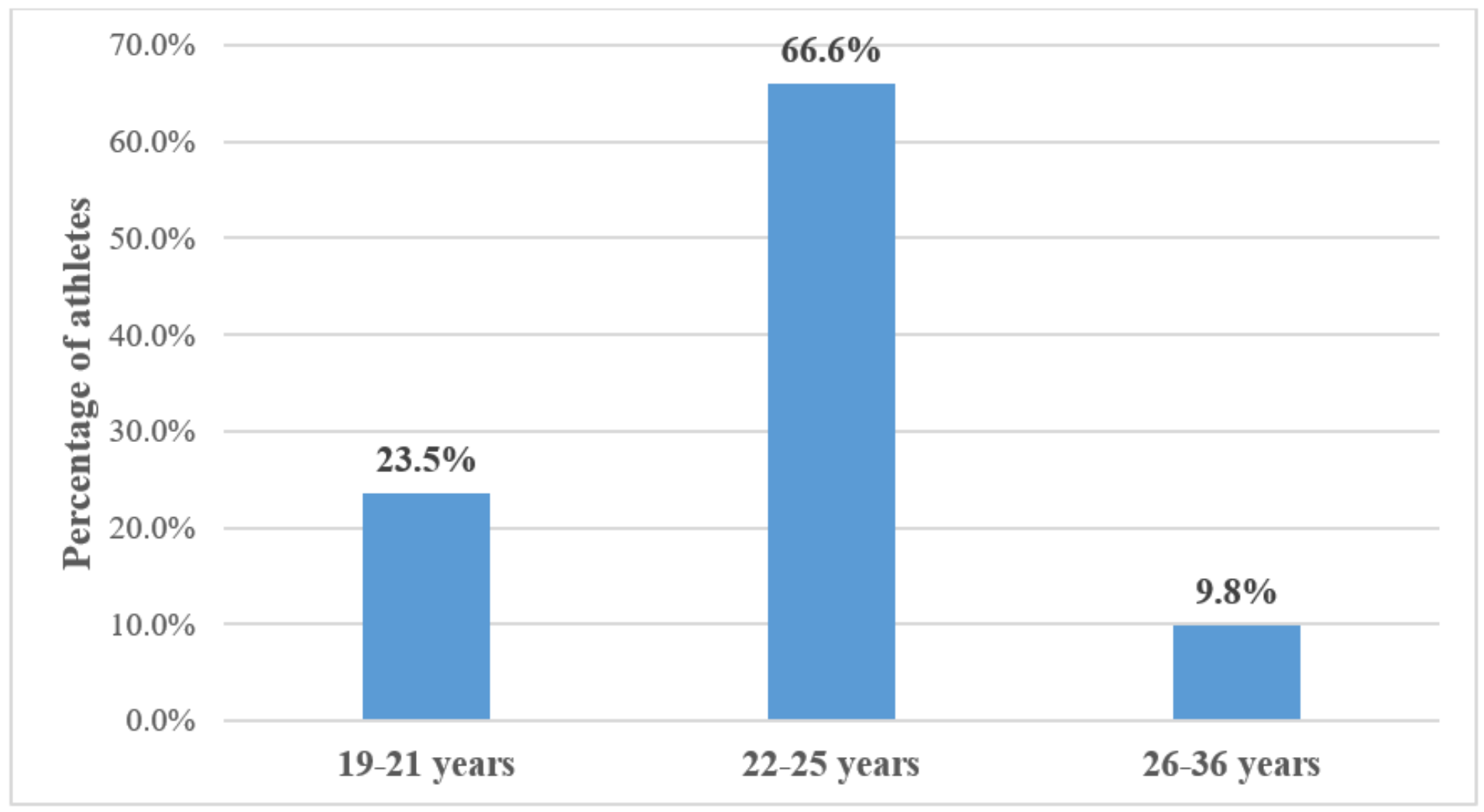

\section{Figure 1}

The graph illustrates the age distribution of the athletes ranging from $19-36$ years. The highest distribution (66.6\%) was established in ages $22-25$ years, followed by athletes who were aged between $19-21$ years. Mean age $=23.6( \pm 3.2)$. 


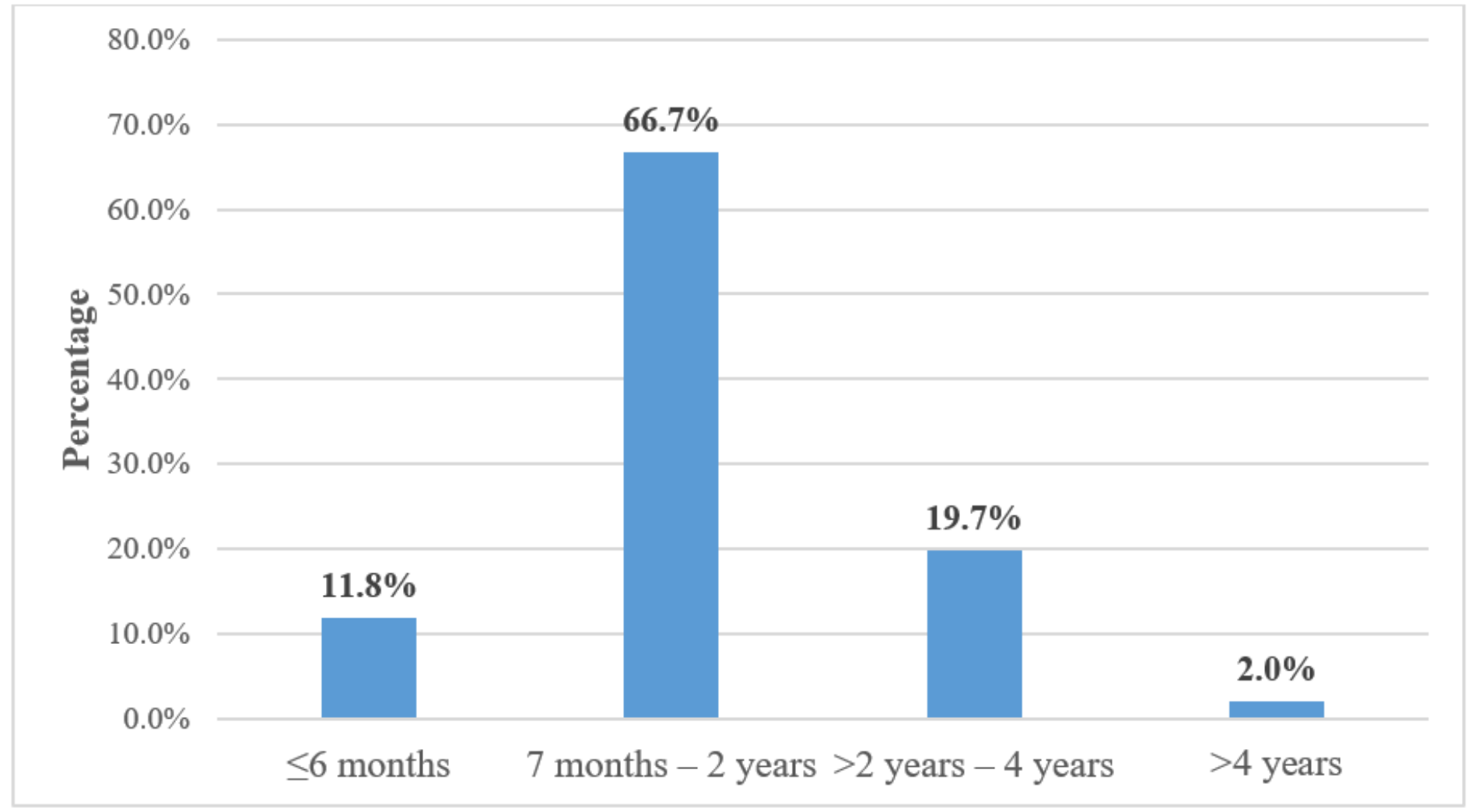

\section{Figure 2}

A Few athletes $(11.8 \%)$ trained as bodybuilders for less $\leq 6$ months, while most athletes $(66.7 \%)$ had been training for $>7$ months to 2 years. Only $2.0 \%$ trained for $>2$ to 4 years as a bodybuilder.

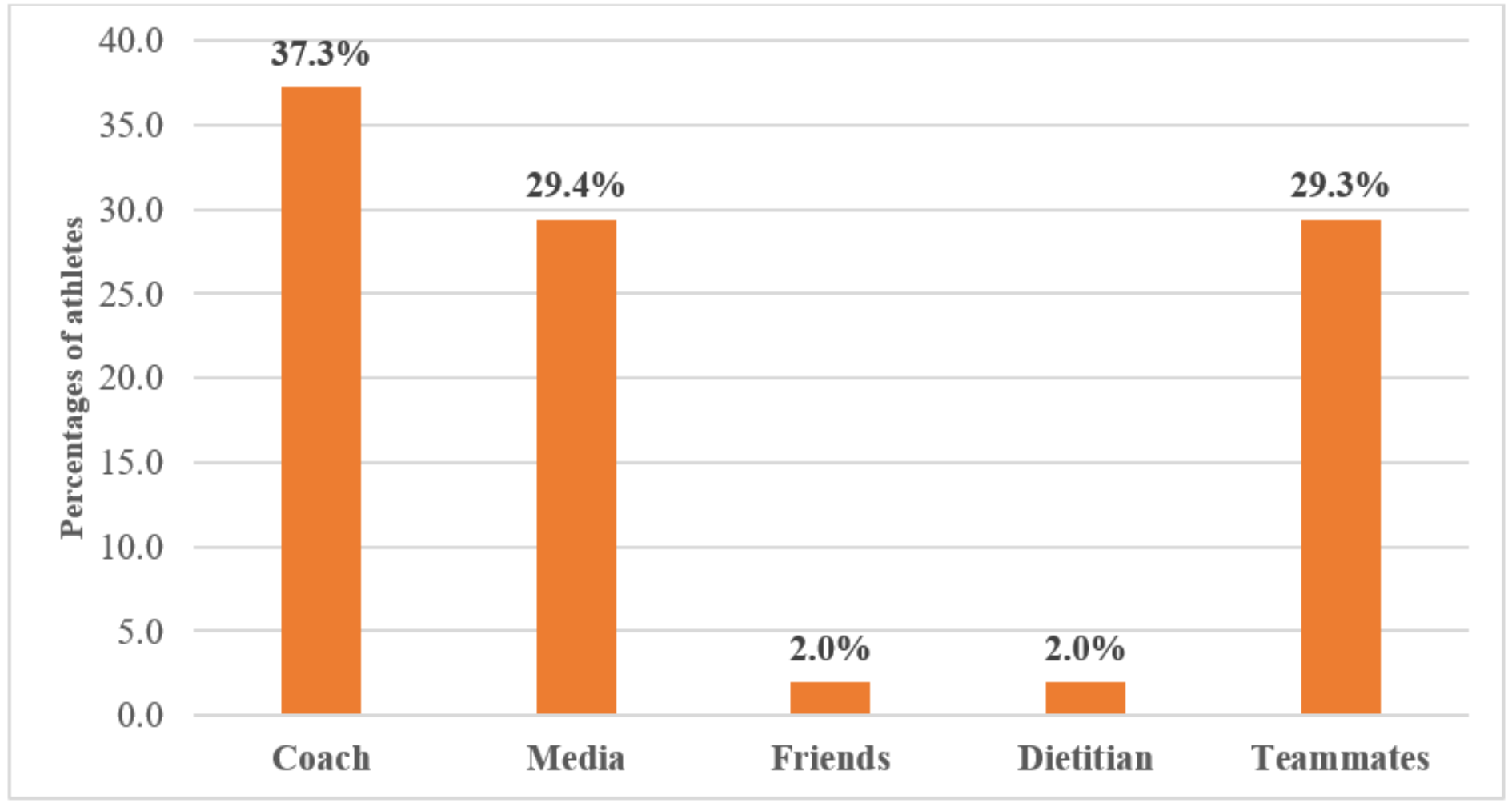




\section{Figure 3}

Most of the athletes (37.3\%) used coaches as their source of nutrition information, while $29.4 \%$ depend on social media and another $29.3 \%$ on teammates. Only $4.0 \%$ of athletes received nutrition education from a Dietitian. 